\title{
Combining project-based and normative approaches for ICZM implementation. Lessons from the Mediterranean.
}

\author{
Raphaël Billé and Julien Rochette, Institute for Sustainable Development and International Relations \\ (Iddri), Sciences Po; raphael.bille@iddri.org; julien.rochette@iddri.org
}

\begin{abstract}
Introduction
Integrated coastal zone management (ICZM) has emerged as a major tool for the implementation of sustainable development in coastal areas. Its application has mobilized considerable human and financial resources for 20,30 or even 40 years depending on the region. However, one observation of the current situation that is hard to dispute is that the world's coastal areas, with few exceptions, have still not been positioned onto the path of sustainable development. Despite the many initiatives and local and/or occasional successes, problems remain and are even intensifying in many regions. Clearly, a serious difficulty therefore exists regarding the scale of the successes obtained. Why do the successes achieved in ICZM remain isolated?
\end{abstract}

A review of the abundant literature on ICZM, together with the close scrutiny of the way it is applied, lead to the unambiguous conclusion that there is a proliferation of ICZM projects. A project is a "temporary organization" (Turner and Müller, 2003) that is classically defined as an "endeavour in which human, material and financial resources are organised in a novel way, to undertake a unique scope of work, of given specification, within constraints of cost and time, so as to achieve beneficial change defined by quantitative and qualitative objectives" (Turner, 1993). Accordingly, the universally acknowledged definition of a programme is as an ensemble of component projects. In this sense, a programme is not fundamentally distinct from a project.

The above definition clearly illustrates that the project is an extremely specific method of organizing action. As a consequence, the domination of the project approach to ICZM raises numerous questions. Firstly, we can wonder whether the project, which by definition is limited in time, constitutes an appropriate form of action since ICZM implementation aims precisely at deep and sustainable transformations of coastal management. Furthermore, the often favoured "pilot" approach (Billé, 2010) generally limits the actual spatial cover of the project relative to the targeted territory. Therefore, how can such an "island of innovation" (Sanders, 2003) be expected to lead to the transformation of routine practices on a larger scale? Could it be through the multiplication of projects in space and time? Or through a combination with other forms of public action? Building on research carried out in the Mediterranean, our objective here is to support this latter hypothesis, highlighting the necessary links between a project-based approach and a normative approach to ICZM, in order to make the best use of the benefits and limitations of each.

\section{The primacy of the project-based approach: benefits and limitations \\ 1.1. An obvious primacy in literature}

If ICZM is generally defined as a process, many authors, largely representative of the literature, dedicate their thoughts, more specifically, towards programmes and projects. For instance Cicin-Sain and Knecht (1998) define ICZM as a process before focusing on implementation through a programme-based approach that is not subsequently challenged. Olsen (1993) rightly 
questions the sustainability of ICZM programmes but does not explainwhy he decides to focus on the issue of programmes in particular. After defining ICZM as a process, Clark (1992) also focuses exclusively on programmes: he does not define the "goals and objectives of ICZM" but directly the "goals and objectives of an ICZM programme".

If nothing predisposes a priori the concept of ICZM to be reduced to a project, it means that this bias must be carried by important forces. Indeed, as noted by Dufumier (2001), "the "cycle of projects' is appealing for its logic: to base decisions on prior knowledge of concrete realities, (...) to conduct actions on the basis of a rigorously defined operational plan, to assess the impact of interventions in order to potentially develop new ones. How could we disagree with such principles that are guided by common sense?".

Beyond this level of appeal, it is clear (Billé, 2004) that the sphere of thought in which ICZM has emerged is largely dominated by researchers and networks based in the United States. However, as underlined by Crozier (1998), in this country "the federal administration, in principle, does not manage - it launches programmes with targeted goals". More broadly, the implementation of programmes or projects that cover the whole possible range of public policies (health, poverty, environment, armed forces, etc..), appears as the usual modus operandi of public authorities. The 1972 Coastal Zone Management Act perfectly illustrates this tradition - a federal law inviting States to develop programmes. This is a peculiarity of the American political and administrative system which, although it has similarities in a number of other countries and organizations across the world, remains clearly distinct from countries such as France, where the project/programme prevalence has remained relatively

limited, at least until the early 2000s. Thus, it seems apparent that the primacy of the project approach in the ICZM literature is due at least partly to the North American influence.

In addition, we have also highlighted the central role played by international donors during the initial phase of development of ICZM (Billé, 2004). In fact the project has already constituted the preferred form of development aid for several decades, to the extent that it represents "the ideal type of a development operation", its "paradigmatic form" (Bako-Arifari and Le Meur, 2001).

Such historical ground helps explaining the prevalence of the project-based approach to ICZM implementation, which far from being purely conceptual actually translates in practice.

\subsection{A primacy that translates in practice}

The proliferation of ICZM projects throughout the world has reached such a level that attempts, initially made during the 1990s (Sorensen, 1993; Cicin-Sain and Knecht, 1998), aimed at their comprehensive enumeration are no longer on the agenda: an exhaustive list would today undoubtedly stretch over hundreds of pages.

The Mediterranean provides a good illustration of this fact. The 2001 White Paper on the management of Mediterranean coastal zones observed that "compared to other regions in the world, the Mediterranean is probably the most advanced in terms of cooperation in ICZM" (UNEP/MAP/PAP, 2001). Indeed, by the mid-1980s, several initiatives had been launched to implement ICZM projects, whether they were strictly of Mediterranean origin or driven by the European Union.

In the framework of the Mediterranean Action Plan (MAP) firstly, the RAC/PAP was in 1978 entrusted with the programme of integrated planning and management, based on a Priority Action Programme (PAP). In 1985, as the MAP was entering its second decade, the Genoa 
Declaration set out several priorities including coastal management, while the fifth ordinary meeting in 1987 of the Contracting Parties decided to redirect the action around integrated planning and management of coastal zones. In this capacity, from 1988 the RAC/PAP launched the first "national pilot projects", renamed Coastal Area Management Programmes (CAMP) in 1989, which were designed for the implementation of ICZM "in selected Mediterranean countries" (UNEP/MAP/PAP/METAP, 2001). Since then, around ten States have benefited from the support of the RAC/PAP to implement ICZM through projects.

Beyond the CAMP, the Mediterranean Environmental Technical Assistance Program

(METAP) has also supported numerous ICZM projects in the Mediterranean basin (Trumbic et al., 1997). Finally, in the framework of the demonstration programme on ICZM launched in 1996 by the European Union, 12 pilot projects were conducted in the Mediterranean while the third generation of the Short and Medium-term Priority Environmental Action Programme (SMAP) has also funded numerous ICZM projects.

\subsection{Benefits of the ICZM project-based approach}

In general, the sequential approach to public action, which encompasses the project-based approach, includes benefits and limitations that have been largely described in political science literature. Thus, according to Muller and Surel (1998), "its first asset is probably to offer a simple analytical framework for public action, which introduces a minimum amount of order in the complexity of actions and decisions that constitute a public policy. (...) Indeed this framework is both general enough to account for any public policy and it allows the formulation of relevant questions (...). The second advantage of the sequential approach, particularly in France, is to break away from the ruling elite's interpretation of public action, to the extent that it enables a sociological approach to substitute the legal interpretation that has remained dominant in the spheres of thought of senior French officials".

By nature, the project-based approach seems ultimately adapted to circumvent excessive bureaucracy, which is sometimes necessary. It is reputed to be more flexible and better able to face the uncertainties of the process and objectives (Turner and Müller, 2003) than the organized action responsible for the routine operations: it provides room for manoeuvre for social and/or technical innovation.

Founded on innovation and learning (learning by doing), the project approach specifically allows experimentation with modalities of concept implementation. The different ICZM projects mentioned above in the Mediterranean have thus enabled the testing of ICZM implementation at several geographic scales, from local to national coast areas. At the same time, they have allowed awareness raising and capacity development for many stakeholders (administration, NGO, private sector...), either directly through the training of local experts, through exchange of experiences, or more indirectly through simple participation in different activities that are linked to the project. In addition, projects frequently help to improve the management capacity by allowing the development of knowledge on the state of the coast and the establishment of monitoring systems.

In the Mediterranean, the project-based approach has greatly contributed to the inclusion of coastal issues in the field of regional cooperation - as shown by the revision of the Barcelona Convention in 1995 - and has also encouraged some States to orientate towards the adoption of a richer legal framework. Finally, by raising awareness of the ICZM concept and "regionalization" of coastal issues, the intense activity regarding ICZM projects has undoubtedly contributed to "floating the idea" of, and then to making possible, the negotiation and adoption of the Mediterranean ICZM Protocol in January 2008 (Rochette, 2007a). This role in the 
preparation of a favourable political background is acknowledged by most stakeholders and in our opinion constitutes a major contribution from the ICZM projects considered.

\subsection{Limitations to the ICZM project-based approach}

In general, problems of the project-based approach have been discussed in great detail elsewhere (see for example Lecomte, 1986 or Bako-Arifari and Le Meur, 2001 within the framework of development aid). We must remember that projects (1) have often shown their limitations in terms of sustainability as soon as financing reaches an end; (2) are not appropriate for the longer time scale required for social change and collective action; (3) suffer from a heightened sensitivity to even very small changes in local conditions (the departure of a project leader for example) or external ones; and finally that they (4) contribute to the fragmentation of the policy. Besides, the linear vision of public action conveyed by the sequential approach tends to underestimate the complexity of public policies and their often chaotic nature (Muller and Surel, 1998).

The project approach to ICZM in particular shows considerable limitations (Billé, 2010). Firstly, it meets the usual difficulties already identified in the framework of development aid: for example we can cite the difficulties of mobilizing "local communities" around projects that are often introduced from the outside, and for a limited duration, or the usually insufficient level of sustainability of the initiated activities, the ambiguities of the relationship between donors and recipients, the never-ending attempts to bypass the state and administrations that never function as required, or the dominant role played by international consultants in some projects that hinders the training of local staff (Trumbic et al., 1997), although such staff are considered to be a major component of any ICZM project (MAP/UNEP, 2001).

Besides, the ICZM project-based approach often leads to the creation of an "island of innovation" (Sanders, 2003), through the temporary application of innovative management methods for a section of coastline within a larger area that overall remains poorly managed. This development is contrary to the very foundation of sustainable development, which requires change in the "development path", i.e. to avoid the multiplication of exceptions, but instead to transform the ordinary.

Finally, the replicability of ICZM projects - which forms the basis of previous and current actions of many organizations - also raises many questions (Billé, 2010). The selected sites often benefit from particularly favourable conditions, one of the selection criteria being the existence of such positive conditions ${ }^{1}$. Consequently, projects struggle to leave the experimental stage to move to the generalization step, since the change of scale rarely happens "naturally".

\section{Recent development of the normative approach to ICZM \\ 2.1. Some examples}

In recent years the acceleration of the littoralization phenomenon and the resulting numerous conflicts have led some States to develop specific legislations for coastal areas: they shift from "coastal-related laws" to "coastal laws", aiming at the application of ICZM. While the U.S. Coastal Zone Management Act of 1972 is a pioneer in this field, other legal frameworks for the coast have been adopted in recent decades. Aiming at the establishment of the coastal zone as a legal object of its own, these normative developments often constitute a major step (Rochette,

\footnotetext{
${ }^{1}$ For example, within the CAMP framework in the Mediterranean, the pre-existence of a strong political will - one of the "rare resources for sustainable development" - is a key selection criterion (MAP/UNEP, 2000).
} 
2007). In the Mediterranean, the 2002 Algerian law establishes some "specific provisions for the protection and enhancement of the coast", regulating human activities on the shore and aiming at developing coastal management plans. In Israel, the 2004 law on the protection of the coastal environment also regulates the planning of the coastal area. In Croatia, a regulation from September 2004 establishes a protected coastal zone and defines the conditions for its development. In total, eight Mediterranean countries now have a specific coastal law, including Spain, France, Turkey, Greece and Lebanon.

Generally, this legal recognition of the specific features of the coast through the development of framework laws contributes to the definition of rules for the conservation and sustainable development of these territories, while incorporating - as applicable - the requirements and principles of ICZM. It can also help to create institutional tools that may elevate the coastal zone to become a genuine subject of public policy.

Finally, ICZM has in recent years made a grand entrance onto the stage of international law through the adoption in January 2008 of an ICZM protocol in the framework of the Barcelona Convention. It constitutes the first supra-state legal instrument specifically aimed at coastal zone management, whereas until now coastal areas had actually been governed by international law in a fragmented manner. So far specific to the Barcelona system, it seems unlikely to remain an isolated example: the sixth Conference of Parties to the Nairobi Convention already decided in early April 2010 to launch a similar process in the WIO region.

\subsection{Benefits of the normative approach}

The normative approach in the implementation of ICZM has many benefits, which often correspond to the limitations of the project-based approach.

In general, legislation firstly enables the compliance of sectoral policies with environmental requirements. Coastal activities, whether industrial or recreational, have direct effects on the environment. Recourse to the legal standard can then ensure that their development is conditional to the protection of natural resources and the environment. It is indeed the essence of the integration principle: transposed into national law, it can be implemented in two ways. Firstly, States may formally recognize the principle itself, for example within a legal provision that has a high rank in the domestic legal order. Accordingly, several States (e.g. Portugal, France, Brazil, Spain or Argentina) have constitutionalized the principle of integration, placing it at the top of the hierarchy of norms. Secondly, domestic law may allow the use of legal tools to ensure implementation. In coastal areas, submitting the development of new activities to prior impact studies, limiting their spatial extent and thus preserving some outstanding ecosystems, or prohibiting any type of development in certain areas of a territory, all require the adoption of specific norms.

Law can also contribute bringing ICZM's five "dimensions of integration" (Cicin-Sain and Knecht, 1998) into national systems, and giving the authorities the tools to ensure implementation. A proclamation by means of a legal text regarding the need to ensure coordination between decision-making authorities is not likely, on its own, to ensure intersectoral integration; conversely, the creation by a specific legal standard of one or more mechanisms responsible for its facilitation may help to achieve this objective. Similarly, how can spatial integration be achieved if not by breaking down the barriers between the coastal environment's planning documents and management tools, that the law confines within either terrestrial or marine spheres? 
The development of a national legal framework for coastal zone management, for example through the adoption of a framework law, also allows more homogeneity in the management of coastal territories at sub-national scales. The use of a framework law then enables the framing of the capabilities of infra-state authorities and the imposition on these authorities to respect minimal rules of coastal zone protection. The decentralization movement that has been observed for 20 to 30 years in many States throughout the world, brings decision making centres closer to the populations concerned, as much as it tends to make the protection of coastal zones dependent on local politics or even clientelism, with highly uncertain outcomes. A new local government may for instance seek to undo a protection scheme that was introduced by the previous political power. In Sardinia, Italy, the ruling majority that has been in power since 2009, is repealing or modifying one by one the instruments of protection that were established by the previous majority - for example, strict limitation of urbanization in coastal areas, coastal land protection, environmental taxation ... - illustrating the consequences of a lack of national standards to set an irreducible level of environmental protection. It would obviously be unrealistic and simplistic to believe that the State is by nature more capable of addressing environmental concerns (Desideri, 2002), but we can note that a national law is more difficult to amend or repeal: to do so would involve a lengthy process, and would present more opportunities for interventions by more powerful and better organized environmental pressure groups. The different politico-administrative scales must therefore be mobilized for what they can bring, including continuity, adaptability and flexibility.

We also note that use of legislation can contribute towards the legitimization and support for ICZM leaders. This is the case, for example, when an internal standard establishes a forum specifically dedicated to ICZM, as has occurred with the ICZM national committees of the Indian Ocean (Billé and Rochette, 2010) and some national agencies in the Mediterranean.

\subsection{Limitations of the normative approach}

Conversely, the existence of a rich normative framework is far from enough to ensure the systematic implementation of ICZM.

The adoption of a coastal law, for example, cannot automatically ensure the coordination between the different activity sectors - sectoral integration - or between different levels of government. Furthermore, the compatibility between sector objectives and activities cannot be decreed but must be politically constructed. Moreover, while legislation can invite the consideration of these requirements and organize procedures to facilitate them, on its own it can neither resolve the difficulty related to a State's administrative culture, or even erect, through the simple acceptance of a legal text, a new management for the coast. In France, the long and painful experience of Sea Valorisation Schemes (SMVM) has shown that the implementation of a legal instrument could be continually blocked by conflicts between sectors and between scales of government.

Legislation efficiency can also be reduced when entire sections of national legislation pursue divergent or contradictory objectives. Legislative inflation, which is a characteristic of development in many States, can lead to this phenomenon.

We must also recognize that there often exists a lag between the adoption of a legal norm and its effective application. Non-adherence to law results from a number of factors, foremost among which is a lack of control mechanisms. To monitor activities carried out in a protected area, a fortiori at sea, requires the deployment of substantial resources that management authorities are not always able to provide. Ensuring that a building permission is delivered in 
compliance with legally imposed requirements necessitates the organization of a particular administrative procedure. More broadly, the application of a norm thus requires the use of monitoring mechanisms that must be organized by an internal system in order to give to the authorities the necessary means, including human resources (guards in protected areas...), technical (ships or aircraft for the surveillance of maritime activities) and administrative (procedures...).

Finally, the recognition of a citizen's right to an administrative or judicial appeal, that allows planning decisions (planning documents for example) to be contested, constitutes a factor that influences the efficiency of a norm, opening opportunities to force public authorities to ensure its effective implementation. However, this right is not currently recognized in all States across the world.

\section{Conclusion: Combining project-based and normative approaches to overcome upscaling issues in ICZM}

The main purpose of this paper was firstly to analyze issues raised by the domination of the project approach to ICZM implementation, and its role in the difficulties encountered by ICZM to achieve success on a large scale. Far from being anecdotal, this primacy reflects, from a theoretical viewpoint, certain influences that are strong but not acknowledged, and from a practical viewpoint it exposes organizational choices for action that lack a strategic perspective. The deployment of the project approach corresponds to an intellectual and administrative automatism which is not intended to address the fundamental strategic question: what form of intervention would be most appropriate in a specific context, taking into account objectives, available means and anticipated resistances? Ultimately, our aim was to contribute to the reduction of this strategic deficit by giving some indications regarding the possible links between what we believe are two key approaches to ICZM: normative and project-based.

Indeed, ICZM implementation cannot be programmed or decreed: while the existence of a legal framework does not in any way guarantee its implementation, an ICZM project, outside of any normative framework that is pre-established or under construction, is almost useless - at least in comparison with the sums of money invested. We have emphasized the weaknesses of the concept of "pilot" experiments, the illusory perspectives of replication, the resulting proliferation of (unsustainable) islands of innovation and the need for a change of scale that the projectbased approach does not enable. Conversely, despite these limitations it is evident that a project becomes truly meaningful as soon as it is associated to a legal framework.

The project-based approach may facilitate the emergence of an adequate normative framework. This framework can therefore be under development, and we have seen how Mediterranean ICZM projects have made possible the development of a regional ICZM protocol.

However, in some instances a legal framework may already be in place and in these situations the purpose of a project should be to facilitate its effective implementation. An ICZM project may initially provide technical support in the implementation of certain aspects of legal texts at the scale of a particular territory. Secondly, a project can provide scientific and technical support and thus complement - and not substitute - the normative approach. If, for example, a legal text aims at the establishment of a coastal strip where building is to be prohibited, considering the anticipated climate changes in the medium and long term, we can imagine that a specific technical expertise is required, which may be provided in the framework of an ICZM project, should the local authorities lack the relevant resources. It is the way the RAC/PAP currently regards the relationship between coastal area management projects and the ICZM protocol - 
and it is also how the initial ICZM programmes began in US coastal states, through the implementation of the 1972 Coastal Zone Management Act.

The principles we propose on the relationships between normative and project approaches are therefore not, in practice, new. However they are far too often ignored or forgotten, notably - but not exclusively - in the framework of public development cooperation. The design of ICZM projects should now reflect their intimate relationship to the normative framework, whether in their objectives, means or activities. It is in this relationship that projects acquire their meaning and legitimacy in terms of delivering changes to coastal management, and it is according to this contribution that they must be assessed.

\section{Acknowledgements}

This paper is based on research undertaken as part of the PROTOGIZC project on "Challenges and opportunities for implementing the Protocol on ICZM in the Mediterranean", funded by the French Ministry of Ecology (Liteau Programme) and the PAP/RAC.

\section{References}

Bako-Arifari, N., Le Meur, P.-Y. 2001. Une anthropologie sociale des dispositifs dudéveloppement, in J.-F. Baré (Dir.) L'évaluation des politiques de développement. Approchespluridisciplinaires, L'Harmattan, Paris, pp.121-173.

Billé, R. 2004. La Gestion Intégrée du Littoral se décrète-t-elle ? Une analyse stratégique de la mise en oeuvre, entre approche programme et cadre normatif, $\mathrm{PhD}$ dissertation in Environmental Sciences (Management), ENGREF, Paris.

Billé, R. 2010. Action without change? On the use and usefulness of pilot experiments inenvironmental management. Surveys and Perspectives Integrating Environment and Society (Sapiens), 3(1): 1-6.

Billé, R. Rochette, J. 2010. Feasibility assessment of an ICZM protocol to the Nairobi Convention. Report to the Conference of the Parties of the Nairobi Convention. UNEP - Indian Ocean Commission, UNEP(DEPI)/EAF/CP.6/INF/20.

Cicin-Sain, B., Knecht, R.W. 1998. Integrated Coastal and Ocean Management, Concepts and Practises, Island Press, Washington, D.C.

Clark, J.R. 1992. Integrated management of coastal zones, FAO Fisheries Technical Paper, N³27, Rome.

Crozier, M. 1998. L'échec de l'évaluation en France tient au modèle jacobin. Revue trimestrielle de l'Institut de la Décentralisation, 38(3): 40-43.

Lecomte, B.J. 1986. Project aid: limitations and alternatives. OECD, Paris.

Muller, P., Surel, Y. 1998. L'analyse des politiques publiques, Montchrestien, Clefs, Paris.

Olsen, S. 1993. Will integrated coastal management programs be sustainable? The constituency problem. Ocean and Coastal Management, 21(1-3): 201-225.

UNEP/MAP/PAP/METAP. 2002. Coastal Area Management Programmes: Improving the Implementation. Split, Priority Actions Programme. 
UNEP/MAP/PAP. 2001. White Paper: Coastal Zone Management in the Mediterranean. Split.

Rochette, J. 2007. Le traitement juridique d'une singularité territoriale : la zone côtière. Étudeen droit international et droit comparé franco-italien, PhD Dissertation in Law, University of Nantes, University of Milan.

Saunders, M. 2003. The "problems with pilots": debating notes. The Evaluator, March.

Sorensen, J. 1993. The international proliferation of integrated coastal management efforts. Ocean and Coastal Management, 21(1-3): 45-80.

Trumbic, I., Hatziolos, M., Cocossis, H., Hénocque, Y., Jeftic, L., Juhasz, F. and B. Kalaora.1997. Assessment of integrated coastal area management initiatives in the Mediterranean: experiences from METAP and MAP (1988-1996). Athens: METAP/MAP/PAP.

Turner, J.R. 1993. The handbook of project based management, Mc Graw-Hill, London.

Turner, J.R., Müller, R. 2003. On the nature of the project as a temporary organization. International Journal of Project Management, 21: 1-8. 